This item was submitted to Loughborough's Institutional Repository (https://dspace.lboro.ac.uk/) by the author and is made available under the following Creative Commons Licence conditions.

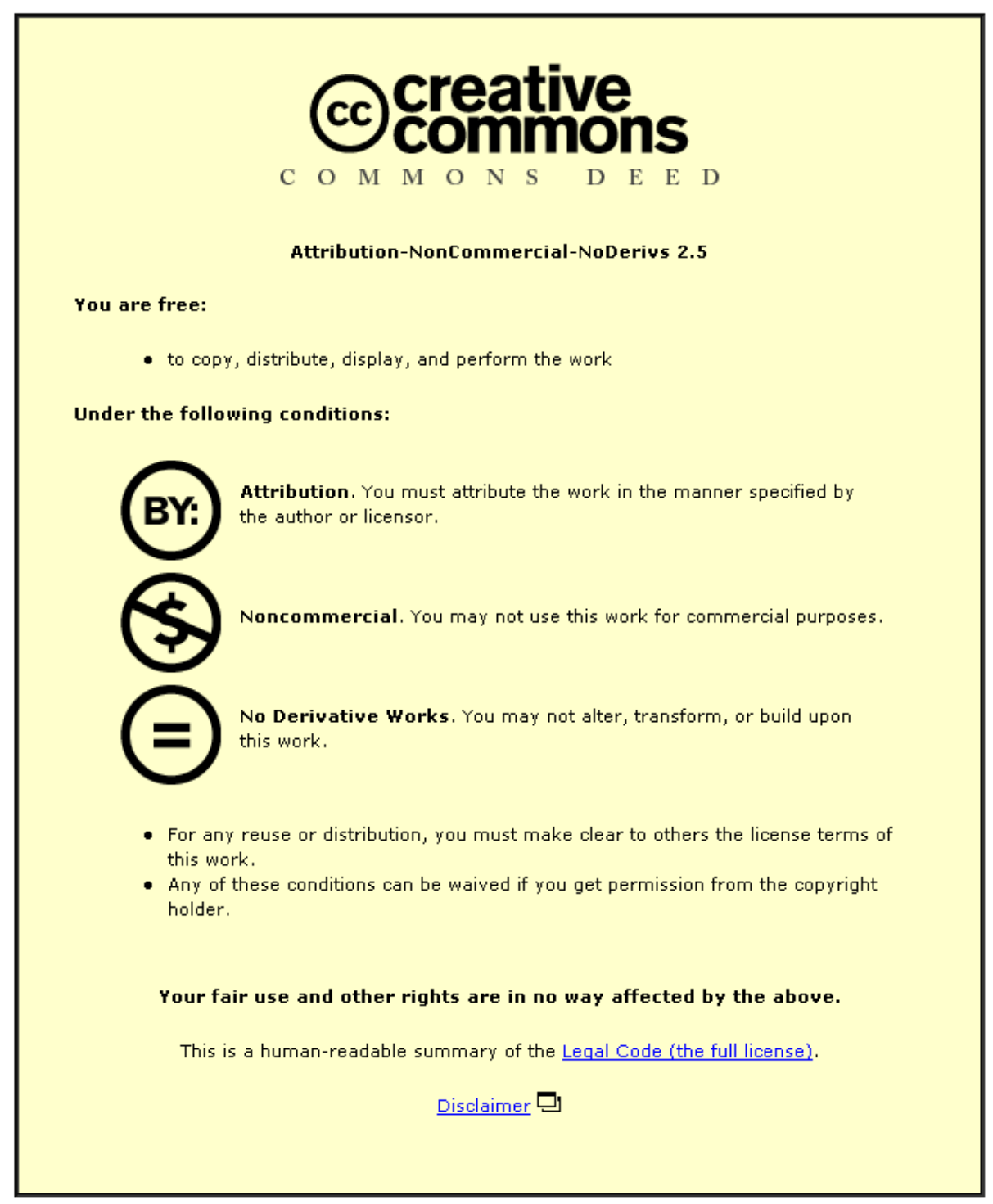

For the full text of this licence, please go to: http://creativecommons.org/licenses/by-nc-nd/2.5/ 


\title{
Implementation of Building Information Modeling (BIM) in Construction: A Comparative Case Study
}

\author{
Steve Rowlinson ${ }^{\mathrm{a}, *}$, Ronan Collins ${ }^{\mathrm{b}}$, Martin M. Tuuli $^{\mathrm{c}}$ and Yunyan $\mathrm{Jia}^{\mathrm{c}}$ \\ ${ }^{a}$ Department of Real Estate and Construction, the University of Hong Kong (*steverowlinson@hku.hk) \\ ${ }^{b}$ Intelibuild Ltd, North Point, Hong Kong \\ ${ }^{c}$ Department of Real Estate and Construction, the University of Hong Kong, Pokfulam
}

\begin{abstract}
Building Information Modeling (BIM) approach is increasingly adopted in coordination of construction projects, with a number of parties providing BIM services and software solutions ${ }^{[1,2]}$. However, the empirical impact of BIM on construction industry has yet to be investigated ${ }^{[3,4]}$. This paper explores the interaction between BIM and the construction industry during its implementation, with a specific focus on the empirical impacts of BIM on the design and construction processes and professional roles during the process. Two cases were selected from recent construction projects coordinated with BIM systems: the Venetian Casino project in Macau and the Cathy Pacific Cargo Terminal project in Hong Kong. The former case illustrates how the conflicts emerged during the design process and procurement were addressed by adopting a BIM approach. The latter demonstrates how the adoption of BIM altered the roles of architect, contractor, and sub-contractors involved in the project. The impacts of BIM were critically reviewed and discussed.
\end{abstract}

Keywords: Building Information Modeling (BIM), implementation, construction. PACS: 00

\section{INTRODUCTION}

The adoption of Building Information Modeling (BIM) processes in the Hong Kong construction industry has evolved in an ad-hoc manner to date with a number of different parties providing BIM services and software solutions. A number of client organizations such as Henderson Land have specified that BIM must be adopted in their design and construction projects. Some clients directly lead the implementation, training, and management of the BIM technology. Others require consultants to offer BIM solutions for each project, in which cases the architects, engineers and contractors appoint independent BIM Consultants to assist in the planning and management process. The larger design consultancy firms such as Ove Arup \& Partners have invested in developing BIM solutions, making the technology accessible to all of their staff. As for contractors, large firms such as Leighton or Gammon use BIM to review construction sequences and to communicate planned tasks to the sub-contractors and local authorities. In September 2008 the Hong Kong Institute of Building Information Modeling (HKIBIM) was established, aiming at promoting and advancing the education, understanding, appreciation and interest in BIM in Hong Kong. If construction projects are to be more effective, this will come as a consequence of greater integration of communications across the temporary project organisation ${ }^{[5]}$.

\section{LITERATURE REVIEW}

The demand for BIM is being driven by the potential for cost savings resulting from shorter project time horizons, less design clashes being issued on the project site which in turn results in fewer delays and cost overruns. As such, the adoption and utilization of the BIM process will require top management support and ultimately need to be demanded by the client ${ }^{[6]}$. Major construction projects involve several key parties that require a great deal of direction in order to complete a project effectively ${ }^{[5,7]}$. Collaboration between key parties, such as architects and 
structural engineers, is critical in accomplishing this goal. The use of BIM technology enables a unified master dataset accusable to all stakeholders of a project, thus facilitating the increasing communication between traditionally segmented parties in the construction process ${ }^{[3,8]}$.

The aim of BIM implementation is to create a centralized shared knowledge resource that contains all the necessary design and operational information about a project ${ }^{[9]}$. $3 \mathrm{D}$ technology had been used to present design proposals, with no real on-site application and no ethos of cooperation amongst team members to drive its use. BIM has taken this concept to the next level by using actual engineering and architectural data to create the 3D models as opposed to creating the models with artistic 3D design software. This allows for a 3D model to be updated by way of changing the database containing the specifications and not the actual model itself. With this advantage, BIM is used to identify and reduce the number of errors and design conflicts and requests for information (RFIs) before the project ever breaks ground ${ }^{[10]}$. Centralizing the dataset also has the benefit of maintaining a consistent format of data which reduces the confusion experienced by different specialists interpreting information.

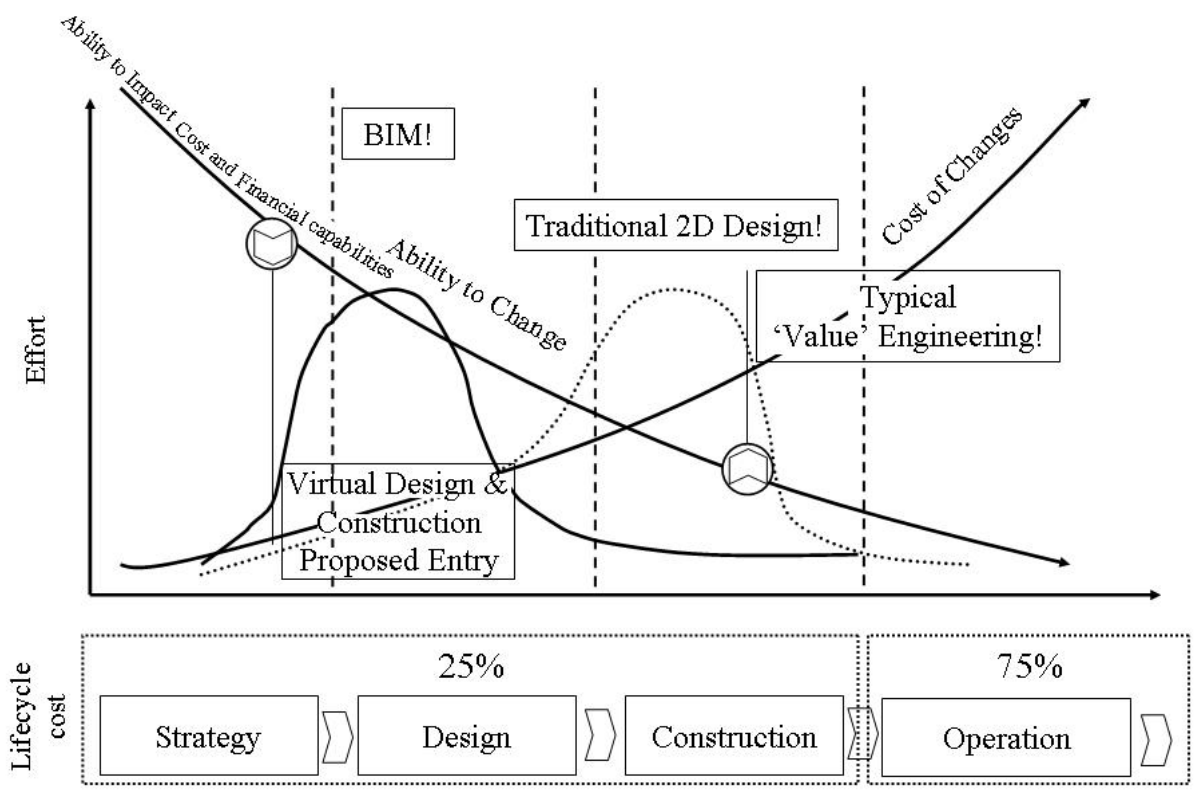

FIGURE 1. Opportunities gained through BIM

Recently, BIM has progressed beyond 3D visual representations to 4D representations of the entire construction process. This allows it to be an incredibly useful tool not only for participants in the design process, but those involved in the building process as well. For example, by simulating the build process, risky construction methods can be identified and designed out before it becomes too late and costly, with obvious occupational health and safety benefits $^{[1,2]}$. Costs can be reduced with the prefabrication of certain elements if the specifications are known well enough in advance, as this typically requires very long lead-times (say, up to 9 months). If requirements for materials are known far enough in advance, structural and architectural elements can be manufactured and delivered to the project using a just-on-time schedule to reduce the need for storage and delays (Figure 1).

A key feature of BIM model is that it does not lay blame; it merely identifies clashes, issues or problems which can be solved collaboratively. In essence, no one loses "face", which is an important cultural concept in Hong Kong $^{[11]}$. Relationship management in construction has its roots in relationship marketing and strategic network competition $^{[12,13]}$. Relational contracting is based on the concept that self-interest motivates parties to enter into contractual relations but competition between parties is necessarily bounded by acceptance of the need for cooperation $^{[14]}$.

This study explores the interaction between BIM and the construction industry during its implementation, with a specific focus on the empirical impacts of BIM on the design and construction processes and professional roles during the process. Two cases were selected from recent construction projects coordinated with BIM systems: the Venetian Casino project in Macau and the Cathy Pacific Cargo Terminal project in Hong Kong. 


\section{CASE STUDIES}

\section{Case 1: the Venetian Casino, Parcel 5 \& 6, Cotai, Macau}

The construction of the Venetian Casino in Macau was managed by Hsin Chong Mace as Management Contractors. Following the traiditinal way of working, the structural engineers and the architects would work on separate sets of schematics which would need to be updated and coordinated as problems are identified, requiring a great deal of organisation and paperwork. During Phase One of the development, there were a number of complex design co-ordination issues between the architectural GRC façade panels and the in-situ structural concrete frame. The issues were causing delays on site while RFIs were issued to the engineering and architectural consultants for resolution.

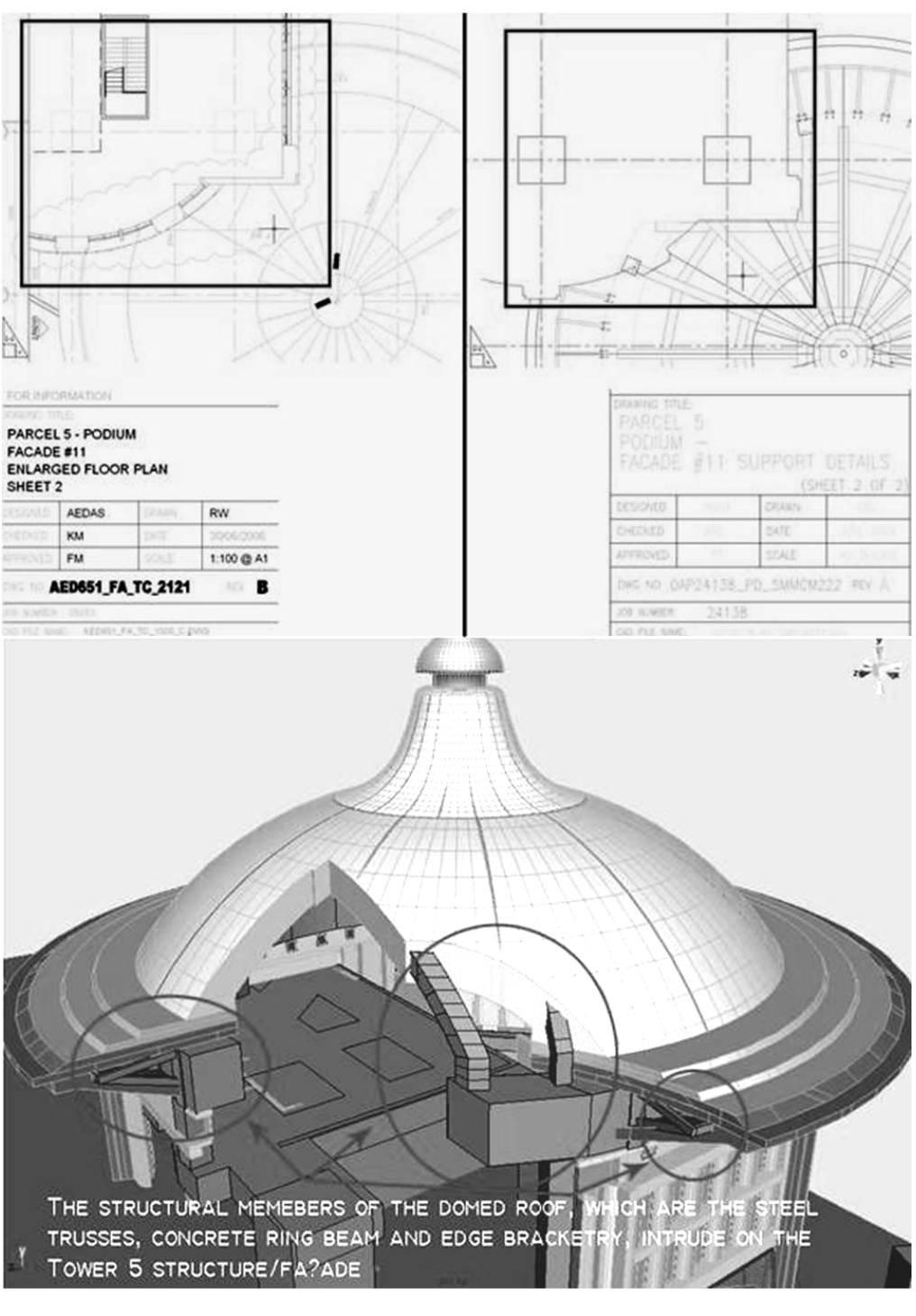

FIGURE 2. Clash and error detection on the Venetian project

The design for the development of Parcel 5\&6 by The Venetian Casino involves a podium façade with a design reflecting Balinese styles. The $250 \mathrm{~m}$ long elevation along the Cotai Strip consists of 18 different themed facades which are all inter-connected. The facades are constructed using GRC precast panels which are supported by a cast in place reinforced concrete frame structure. During the design, tender and construction of the first phase of the 
Venetian Casino, there were a number of design integration problems between the Venetian themed GRC facades and the concrete structures. The design issues contributed to delays during the tender and construction stages.

In reaction to the challenges on phase one, the client supported the adoption of BIM 3D CAD modeling during the detailed design phase and construction documentation stage before the specialised façade contractor was appointed. A BIM team from the InteliBuild were appointed to work in parallel to the architects and structural engineers to build 3D CAD models to identify design conflicts where structural elements were clashing with architectural elements of the façade. These issues were then resolved by the designers before the drawings were issued to the contractors (Figure 2).

At the commencement of the 12 week detailed design and tender documentation phase for the Parcel 5\&6 Façade project, the BIM team assume their role of coordinators, assembling 3D CAD models from the architects and structural engineers $2 \mathrm{D}$ CAD drawings. The BIM co-ordination engineers worked on tasks as to identifying design clashes, conflicting information and missing details on the consultant's drawings. A schedule of work was developed with the design team to integrate the 3D CAD design validation review into the overall design co-ordination process. The 3D structural modeling team assembled the structural frame model from the Arup 2D CAD drawings. The 3D architectural modeling team built the GRC façade models from the architects' 2D CAD drawings.

As the design for each of the 18 themed facades was completed, a report was compiled by the BIM coordinators identifying issues which required the attention of the architects and engineers. These issues included conflicting information between architectural plans, sections and elevations, misalignment and setting out issues between the structural framing and GRC panels and many other technical queries. These issues were previously discovered by the main contractor on site.

The architect and structural engineers issued drawings to the BIM team on a weekly basis. One week later a design co-ordination workshop was facilitated by the client to review the design progress and to resolve the technical queries raised from the $3 \mathrm{D}$ modeling process. The 3D models were used throughout the design co-ordination process to review details and to illustrate different design conditions. The 3D models became the focal point for discussions between the client, architect and engineers. The architects and engineers made design changes and revised their respective $2 \mathrm{D}$ drawings according to decisions made during the co-ordination work-shops. The updated drawings were then incorporated in the 3D CAD models to ensure that the issues raised previously were fully resolved.

There was an initial resistance from the Architects and Engineers to the inclusion of an independent check by the 3D CAD modeling team. But designers soon became fully engaged when they found the BIM models and technical query process facilitate better understanding of the issues. At the end of the scheduled 12 week tender documentation process, the architects and engineers produced a set of fully coordinated design drawings and the 3D Modeling consultant produced a detailed interactive model of the podium façade. The 3D model was included with the tender documents issued to the specialist façade contractors. As the client noted, the BIM coordinated tender was completed in a shorter duration than the previous phase.

\section{Case 2: the Cathay Pacific Cargo Terminal, Hong Kong}

The project is located on the south side of the Hong Kong International Airport platform the Cathay Pacific (CX) cargo terminal facility, costing roughly USD $\$ 500 \mathrm{M}$. The facility will be the largest air cargo terminal in the world (when measured by tonnage per square metre) with a target throughput capacity of 2.6 million tonnes of cargo per annum. At peak times, the cargo terminal will process more than 75 flights per day with each flight containing up to 110 tonnes of cargo from silver bullets (converted 747 cargo carriers) or up to 25 tonnes from passenger planes.

The client specified that the design must be coordinated using the BIM process from the very beginning of the design stages. CX was determined to use the latest technology available to reduce the risk of delays and cost overruns on the complex fast-track building. The cargo facility is a structure with a very specific purpose that requires extensive mechanical, drainage, ventilation, electrical, and specialised mechanical systems. As the design, drawings and specifications for these systems are incorporated into the BIM, a detailed clash detection analysis matrix can be implemented to identify and eliminate any design conflicts between various systems (cargo handling, structural, architectural, municipal systems, specialised systems).

There are different types of clashes that must be indentified in a project such as this. A hard clash will exist where piping or other systems are passing through or otherwise interfering with structural or architectural elements. This could cause a delay on site that might require an RFI if overlooked during the design process. Cargo enters the facility on 6 tonne pallets which are then processed by the Materials Handling System (MHS). The MHS consists of a semi-automated assembly of roller-decks, which move the cargo pallets laterally while large hoists are used to raise or lower the pallets vertically between levels. This requires the BIM to account for the different systems that may 
have a clearance clash with the "kinetic envelope" of the cargo pallets as they are moved and process throughout the facility.

Clashes were identified using a specialized clash matrix that incorporates design specifications and operational requirements (headroom, MHS specifications, structural and architectural co-ordination, and MEP co-ordination) into the analysis (Figure 3). The analysis is done on a priority basis and issues are resolved before any construction ever begins. This is a continual process and a dedicated engineer works on this continuously through-out the design co-ordination process. This has resulted in far less on-site RFIs, cost over-runs, and delays.

The proactive approach adopted by $\mathrm{CX}$ in this project has resulted in smoother operation and forced traditionally segregated elements of the design process (structural engineers, architects, MEP, etc) to collaborate in a systematic fashion from the outset. This has required the extensive retraining of key personnel to use standardized systems and software platforms to ensure that there is consistency in the design and format of data. The challenge for the BIM manager, as reflected by the project director, is the demand of commitment from designers and contractors. Resistance come from the professional inertia of coming back to 2D: "at times we have had to insist that sliding back to 2-D methods is just not acceptable". The approach proved to be bringing about the intended culture change in the industry.

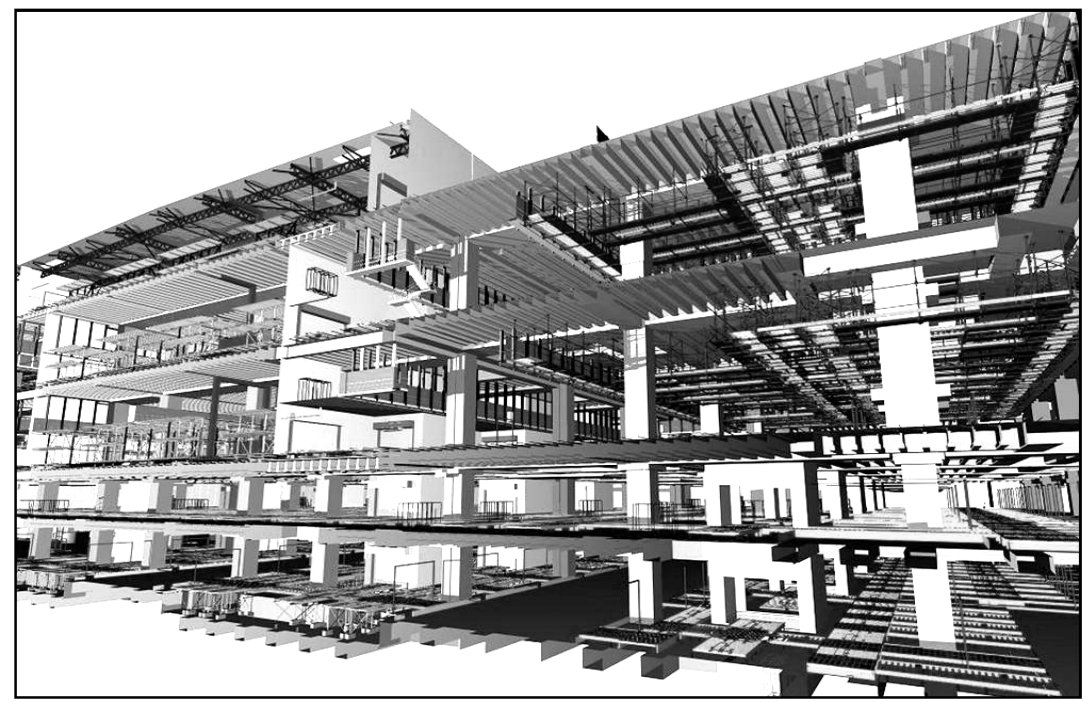

FIGURE 3. Scheme of the new CX cargo terminal of Hong Kong

\section{DISCUSSION}

Value creation by members of a temporary project organisation requires the involvement of the entire project supply chain. BIM coordination helps close the communication gap with other team members. However, such a fundamental change in the culture of the industry cannot be brought about by technology alone. It is essential that processes and procedures are put in place on top of the procurement system ${ }^{[4]}$. The cooperation and collaboration among stakeholders depend to a great extent on the management of relationships within the project team, a temporary multi organization ${ }^{[5,8]}$. The case studies indicate that the social infrastructure and relationship management are to be developed to underpin the implementation of BIM. As these infrastructures now are starting to coalesce the opportunity for true cooperation is now beginning to emerge ${ }^{[14]}$.

The BIM process creates new challenges by modifying the timing of the payment structure of projects, with more money being expended "up-front" ${ }^{[7]}$. The BIM demands a complete model before construction begins where clashes and other problems can be resolved virtually before encountered on site. Resistance to BIM occurs in situations where architects and engineers, who traditionally expect the majority of the workload to be in the latter half of the design phase as RFIs are issued, have their workload shifted towards the beginning of the design phase. The cash flow is modified among consultants, which demands a culture change in the current procurement system. 


\section{CONCLUSION}

Through the analysis of two cases, this study examined the interaction between BIM and the construction industry during its implementation, with a specific focus on the empirical impacts of BIM on the design and construction processes and professional roles during the process. The former case illustrates how the conflicts emerged during the design process and procurement were addressed by adopting a BIM approach. The latter demonstrates how the adoption of BIM altered the roles of architect, contractor, and sub-contractors involved in the project. The findings indicate that business success alone is insufficient as a driver for managers to justify the implementation of integrated ICT strategies, unless there is strong support for such change from ICT champions (preferably senior management within the organisation). A change of culture is necessary and the implementation of BIM in project delivery must be accompanied by a relationship management approach and, preferably, a move towards more integrated procurement systems, such as alliance and design build approaches.

\section{ACKNOWLEDGMENTS}

The authors would like to acknowledge the work of R. Richard Switzer in the preparation of this paper.

\section{REFERENCES}

[1]Hu, Z., J. Zhang, and Z. Deng, Construction Process Simulation and Safety Analysis Based on Building Information Model and 4D Technology. Tsinghua Science \& Technology, 2008. 13(Supplement 1), pp. 266-272.

[2]Schlueter, A. and F. Thesseling, Building information model based energy/exergy performance assessment in early design stages. Automation in Construction, 2009. 18(2), pp. 153-163.

[3]Froese, T.M. Information management for construction. in 4th International Workshop on Construction Information Technology in Education. 2005. Dresden University of Technology, Germany.

[4]Suermann, P.C. and R.R.A. Issa, BIM effects on construction Key Performance Indicators (KPI) survey. Journal of Building Information Modeling, 2007. Fall(2007), pp. 26-27.

[5]Rowlinson, S., The temporal nature of forces acting on innovative IT in major construction projects. Construction Management and Economics, 2007. 25, pp. 227-238.

[6]Tantoush, T. and S. Clegg, CADCAM integration and the practical politics of technological change. Journal of Organizatinal Change Management, 2001. 14(1), pp. 9-27.

[7]Succar, B., Building information modeling framework: A research and delivery foundation for industry stakeholders. Automation in Construction, 2009. 18(3), pp. 357-375.

[8]Rowlinson, S., M.M. Tuulimm, and T.Y. Koh, Stakeholder management in Hong Kong, in Construction Stakeholder Management, E. Chinyio and P. Olomolaiye, Editors. in press, Wiley-Blackwell: Oxford.

[9]Smith, D., An introduction to Building Information Modeling (BIM). Journal of Building Information Modeling, 2007. 2007(Fall), pp. 12-14.

[10]East, E.W. and W. Brodt, BIM for construction handover. Journal of Building Information Modeling, 2007. Fall(2007), pp. 28-35.

[11]Phua, F.T.T. and S. Rowlinson, Operationalizing culture in construction management research: a social perspective in the Hong Kong context. Construction Management and Economics, 2004. 22(9), pp. 913-925.

[12]Bresnen, M. and N. Marshall, Partnering in construction: a critical review of issues, problems and dilemmas. Construction Management and Economics, 2000. 18(5), pp. 587-598.

[13]Cherns, A.B. and D.T. Bryant, Studying the client's role in construction management. Construction Management and Economics, 1984. 2(2), pp. 177-184.

[14]Anvuur, A.M. and M.M. Kumaraswamy, Conceptual model of partnering and alliancing. Journal of Construction Engineering and Management, 2007. 122(3), pp. 225-234. 